patient cannot be promoted he or she must be so informed.

8. Whatever the psychiatrist has been told by the patient, or has noted during examination or treatment, must be kept confidential unless the patient releases the psychiatrist from professional secrecy, or else vital common values or the patient's best interest makes disclosure imperative. In these cases, however, the patient must be immediately informed of the breach of secrecy.

9. To increase and propagate psychiatric knowledge and skill requires participation of the patients. Informed consent must, however, be obtained before presenting a patient to a class and, if possible, also when a case history is published, and all reasonable measures be taken to preserve the anonymity and to safeguard the personal reputation of the subject.

In clinical research, as in therapy, every subject must be offered the best available treatment. His or her participation must be voluntary, after full information has been given of the aims, procedures, risks and inconveniences of the project, and there must always be a reasonable relationship between calculated risks or inconveniences and the benefit of the study.

For children and other patients who cannot themselves give informed consent this should be obtained from someone close to them.

10. Every patient or research subject is free to withdraw for any reason at any time from any voluntary treatment and from any teaching or research programme in which he or she participates. This withdrawal, as well as any refusal to enter a programme, must never influence the psychiatrist's efforts to help the patient or subject.

The psychiatrist should stop all therapeutic, teaching or research programmes that may evolve contrary to the principles of this Declaration.

\title{
GORRESPONDENGE
}

\section{DEPENDENCE/ADDICTION GROUP}

Dear Sir,

The Royal College of Psychiatrists has four Specialist Sections (Mental Deficiency, Child Psychiatry, Psychotherapy and Forensic Psychiatry) and there are two special Groups dealing with Social Psychiatry and the Psychiatry of Old Age (Council has recommended that the latter should now become a Section). There is no Group to deal with the problems of dependence on alcohol, tobacco and other drugs. There have been informal discussions among members of the College who work with or are interested in these problems, and preliminary consideration has been given to setting-up such a Group. It is proposed to hold a meeting at the College at $4.30 \mathrm{pm}$ on Wednesday, 25 January 1978 , to discuss this suggestion further.

It would be helpful if College members could let me have any comments they may have about this proposed Group and let me know if they would be interested in, and able to come to, this meeting. It would also be helpful to know who might wish to join such a Group if it were set up, and I would be glad to have the names of anyone interested, even if unable to attend the meeting.
If at this meeting it is decided that it would be reasonable to start a Group, the procedure would be to send a formal proposal to Gouncil. It would also be desirable to elect provisionally a Chairman and Secretary.

Tooting Bec Hospital,

Thomas Bewley

Tooting Bec Road,

London $S W_{I 7} 8 B L$

Dear Sir,

\section{IS IT GRICKET?}

The Scribe's Column (Bulletin, November 1977) on the 'Hospital Cricket Advisory Service' made enjoyable reading. We had the chance to applaud some splendid bowling, the dismissal of several inept batsmen, and a couple of easy catches.

This skilful parody illustrates the folly of replacing, in our hospital service, long traditions of experience and professional skill with half-baked dogma. Psychiatry, in addition, is suffering from the heavy roller of bureaucracy on the one hand, and on the other an aggressive watering of the pitch by the many disgruntled members who have not been selected for the first eleven. But what is so different in the 